\title{
Indirect requests, relevance, and politeness
}

\begin{abstract}
In the relevance-theoretic framework, maximal relevance is achieved when processing effort is minimized and cognitive effects are maximized. In line with the presumption of optimal relevance, the addressee (A) of an utterance not only assumes that the speaker (S)'s utterance is relevant enough for it to be worth processing: he expects $S$ to choose an utterance that is the most relevant one compatible with her preferences and her abilities. In this paper, I offer a detailed relevance theoretic analysis of conventionalized indirect requests (IRs) such as Can you + verbal phrase (VP)? in terms of maximal and optimal relevance. I show that, according to standard relevance theory, the request meaning of Can you VP? IRs is communicated as an implicature, which means that it is, in theory, more complex to access than when it is explicated by the imperative counterparts (VP!) of IRs. However, the existence of pragmatic routines, supported by recent experimental evidence, enables short-circuited inferencing of the IR meaning. These IRs do not increase processing costs, which indicates that, as imperatives, utterances Can you VP? can be maximally relevant for the performance of requests. Arguing that politeness effects are not systematically communicated with IRs, I propose that these indirect expressions are preferred because they enable speakers to avoid impoliteness effects, and they are, in such circumstances, optimally relevant stimuli for requesting.
\end{abstract}

\section{Introduction}

Sperber \& Wilson's (1995) relevance theory (RT) regards linguistic communication as a form of ostensive-inferential communication. In RT, an ostensive stimulus is a stimulus designed by an individual in order to attract another individual's attention. Two kinds of intentions are involved in this process. The informative intention is the speaker's (S) intention to modify the addressee's (A) cognitive environment, for instance to make (more) manifest a set of assumptions. S's communicative intention amounts to make her informative intention mutually manifest to $S$ and A (1995, 54-64). ${ }^{1}$ A thought is the conceptual representation communicated by means of an utterance; an assumption is a thought that an individual considers as being about the actual world.

To understand the meaning conveyed by an utterance, A takes the utterance as a piece of evidence about S's intention to convey some information. That is, A infers S's informative intention from the communicative intention he attributes to $\mathrm{S}$. To do so, he must give the priority to an interpretation that will satisfy his expectations of relevance. That is, A assumes that $\mathrm{S}$ makes a relevant contribution, viz., that the processing efforts required from himself are sufficiently counterbalanced by the utterance's effects on his cognitive environment (communicative principle of relevance). RT conceives of human cognition as geared towards

\footnotetext{
${ }^{1}$ The cognitive environment of an individual consists in the set of assumptions that are manifest to him/her at a given moment.
} 
the minimization of processing costs and the maximization of cognitive effects (cognitive principle of relevance). ${ }^{2}$ Maximal relevance is achieved, for any given degree of effort, when the effects resulting from that effort are greatest, or, for any given level of effect, when the effort required for deriving those effects is minimized (Sperber \& Wilson 1995: 266). Optimal relevance is achieved if the chosen stimulus is the most relevant one compatible with the speaker's personal preferences and abilities (Sperber \& Wilson 1995: 266-271). S's preferences include moral, prudential, and stylistic judgments. Examples of cognitive limitations are S's state of knowledge, degree of tiredness, the amount of time she has to produce an utterance, etc. The consequence is that maximal and optimal relevance do not necessarily coincide: a stimulus that is maximally relevant (Shut up! to tell a colleague to shut up) might come to the speaker's mind, before being discarded because it does not match her moral preferences (it sounds patronizing to her).

In this paper, I propose an analysis of indirect requests (IRs) such as Can you VP?, called "conventional(ized)" in the literature, within the standard RT framework. Even though IRs have been (and still are) the target of intense theoretical debate and empirical investigation (see Ruytenbeek 2017 for a recent review), they have rarely been addressed by relevance theorists (but see Groefsema 1992 and Jacobsen 2010). A discussion in terms of costs/effects has been proposed, for instance, in the case of metaphorical meaning (Gibbs \& Tendahl 2006). However, it is unfortunate that the relationship between the interpretation of IRs, their processing costs, and their cognitive effects has been left unexplored.

Let us take an IR such as (1), and the corresponding imperative request in (2). In what follows, I assume that there are situations where the conventionalized IR (1) and the imperative (2) are two plausible alternative ways to perform one and the same request speech act in that sort of situation, and I will compare these two types of linguistic expressions qua requests. Such contexts are informal conversations between friends or intimates of equal status (for empirical evidence supporting this assumption, see Flöck 2016, Chapters 4-5).

(1) Can you close the window?

(2) Close the window.

The questions I would like to discuss are the following. When (1) and (2) are uttered as a request to close the window, can we expect these expressions to differ in terms of their respective processing costs and cognitive effects for the addressee? All other things being equal, which expression is more likely to be, according to RT, a maximally relevant stimulus in a particular context? And what makes either of these alternatives optimally relevant? Since these questions cannot be answered solely on theoretical grounds, I will also address relevant experimental data.

\footnotetext{
${ }^{2}$ In RT, cognitive effects are contextual effects in an individual (Sperber \& Wilson 1995, 265).
} 
Here is how the rest of this paper unfolds. In Section 2 I will argue that, for standard RT, the "request" assumptions communicated by conventionalized Can you VP? utterances are best reconstructed as strong implicatures. Section 3 will be devoted to differences in the propositional attitudes of potentiality and desirability encoded by imperative vs. interrogative sentences. I will show why, according to RT, extra inferential steps are predicted for conventionalized IRs. In Section 4 I will argue that, all other things being equal, in a situation where a speaker performs the act of requesting, both an imperative stimulus and a conventionalized IR expression can achieve maximal relevance because the latter do not increase the processing costs relative to imperatives. In that section, a discussion of the politeness of IRs will be provided, in which we will see that politeness assumptions rarely count as cognitive effects triggered by Can you VP? IRs. Finally, I will propose that IRs are optimally relevant in many situations because they are the most relevant stimuli available to speakers and they enable them to avoid being perceived as impolite (without necessarily communicating the assumption that "they are being polite").

\section{Implicatures or explicatures?}

Before discussing in detail the costs and effects of IRs from the perspective of RT, it is worth distinguishing between the cases where a request is an explicated vs. an implicated assumption communicated with an utterance of a sentence. In this section, I will show that, according to standard RT, both conventionalized IR expressions (e.g., Can you VP?) and expressions for which the IR meaning is less strongly entrenched, such as negative state remarks (often called "non-conventionalized IRs" in the literature), should be analysed in terms of implicatures.

In RT, the comprehension of an utterance involves two processing modules (see, e.g., Wilson \& Sperber 1993). The syntactic module is devoted to decoding the logical form (LF) from the sentence; the pragmatic module takes the LF as an input to yield the communicated content. Carston (2002, 72-73) stresses, furthermore, that these two modules operate in parallel, as pragmatic processing comes into play for each word and the next, before the complete semantic representation of the utterance is decoded. For example, for an utterance of (3), pragmatic information is accessed in order to identify the referent of the pronoun you as soon as the word you is heard/read - even though, at this point, the decoding of the utterance is not complete.

(3) What did you eat this morning?

In RT, a conceptual representation that is communicated by means of an utterance is called a "thought", and an "assumption" is a thought that an individual considers as being a conceptual representation of the actual world. At the level of pragmatic processing, RT draws an important distinction between two sorts of inferred assumptions: explicated assumptions (explicatures) and implicated assumptions (implicatures) (Sperber \& Wilson 1995, 176-202; Carston 2002, 116-152). Explicatures provide a rational warrant for the derivation of implicatures. That is, deriving an explicature can serve as a premise in the inferential process 
leading to the identification of another communicated assumption, such as an implicature. However, implicatures need not be derived after explicatures, but they can precede explicatures in the inferential process; a mutual adjustment between explicatures and implicatures is thus expected (see Jary 2013). This is because the inferential process is not linear and backward inference is possible.

For explicatures, the decoding module yields a propositional form. Explicatures are fleshed out by pragmatic enrichment and/or modulation of the LF. In the case of utterances of declarative sentences, the propositional form is a base-level explicature. For instance, (5) is a possible base-level explicature corresponding to the sentence uttered in (4), and (6) would be a higher-level explicature constructed by development of the base-level explicature in (5), according to which S performs an act of "saying".

(4) It's cold in here.

(5) It is cold in the room where S and A are sitting.

(6) $\mathrm{S}$ is saying that it is cold in the room [etc.].

The explicature in (5) can also give rise to a higher-order explicature such as (7), which is another description of S's act in terms of a speech act.

(7) $\mathrm{S}$ is informing/reminding A that it is cold in the room [etc.].

In higher-order explicatures such as (6)-(7), the base-level explicature (5) is embedded within a higher-level description.

Unlike explicatures, implicatures do not build on the LF of the sentence, but they are inferred from the utterance plus contextual background. A possible implicature of (4) is, for example, (8), in a situation where it is mutually manifest to $\mathrm{S}$ and $\mathrm{A}$ that $\mathrm{S}$ wants $\mathrm{A}$ to close the window left open.

(8) $\mathrm{S}$ is requesting that A close the window.

In order to flesh out the assumption (8) from (4), the interpreter should combine the communicated explicatures with features of the particular context of utterance. This amounts to inferring the explicature (5), and possibly also (6) or (7), and taking into account contextual information such as, for instance, that people do not appreciate when it is cold in a room, and rules regulating human interaction such as that it is not respectful to leave a window open when someone is getting cold (cf. Pérez Hernández 2013, 137-139).

Thus, in RT, anything that is communicated without being a development of the LF encoded by an utterance is implicated. Now, the question is, from the perspective of RT, whether in conventionalized IRs such as (1) the "request" assumption such as (8) is communicated as an implicature - as in the case of (4) - or, rather, as an explicature of the utterance.

(1) Can you close the window? (repeated) 
For (1), the interpreter should derive an explicature such as (9) and combine it with contextual information including that the answer to the question expressed is obvious and that $\mathrm{S}$ is not expecting A to answer her question.

(9) $\mathrm{S}$ is asking whether A can close the window.

A mutual adjustment between explicatures and contextual background would thus be necessary in both (4) and (1).

Now, assuming both (4) and (1) can be used to request that A close the window, there is an obvious difference between these two request forms. In (1), the "request" meaning (as well as A's future action) is strongly associated with the linguistic content of the utterance: A's expected action is explicitly expressed in the linguistic content of the sentence uttered. In (4), by contrast, the form of the utterance gives no cues as to its potential request meaning. All other things being equal, the request meaning is therefore expected to be weaker, or "less salient", in such negative state remarks than in conventionalized IRs (Panther \& Thornburg 1998). Available experimental evidence supports this view (e.g., Holtgraves 1994; for a discussion see Ruytenbeek 2017).

The notion of the strength of an implicature could be helpful here (Wilson \& Sperber 2002). Weakly implicated assumptions contrast with strongly implicated ones, the recovery of which "is essential in order to arrive at an interpretation that satisfies the expectations of relevance raised by the utterance itself" (269). For instance, in a situation where a window has been left open and the heating has been turned off, the implicature (8) conveyed by means of (4) will compete with other interpretations that would also satisfy A's expectations of relevance (e.g., that A should bring S's scarf or jumper to her, that A should turn the heating on). The relative strength of the implicature communicated in that situation would be lower than in a situation where the window is open but the heating is already on (the only plausible response in that context would be to close the window).

(4) It's cold in here. (repeated)

(8) $\mathrm{S}$ is requesting that A close the window. (repeated)

Inasmuch as the range of assumptions potentially achieving relevance is smaller in the case of a Can you VP? utterance such as (1) (the expected action is mentioned in the proposition expressed, i.e., in the VP), it is to be expected that the request assumption will be more strongly implicated than in the case of (4). Summing up, while both (4) and (1) can be used to request that the addressee close the window, these utterances can be distinguished in terms of the relative strength of their request implicature.

An alternative view is Groefsema's (1992) account of the interpretation of requests involving the modal can such as (1), which is, to the best of my knowledge, the only detailed 
treatment of conventionalized IRs in RT. ${ }^{3}$ According to her, unlike in the case of (4), the request assumption conveyed with (1) is an explicature, and not an implicature, of the utterance. In her account, can has a 'direct' request interpretation in such examples. To be more precise, the "request" meaning of a Can you VP? utterance is a direct development of the unitary meaning of can, guided by the communicative principle of relevance. That is, if Groefsema is right, there is nothing special to (1): a higher-order explicature, (8), is derived after enrichment of the logical form (LF) of the sentence uttered, much in the same way as an imperative such as (2) yields the explicature in (8).

(2) Close the window. (repeated)

Following Wilson \& Sperber's (1988) analysis of the interrogative mood (see more on this in Sections 3.1 and 3.3), Groefsema (1992, 131-132) conceives of the utterance of (1) as communicating that the assumption <The addressee can close the window> would be relevant (that is, yield more cognitive effects) if true. According to Groefsema, the LF of (1) is (1'), in a situation where it is mutually manifest that $\mathrm{P}$ is relevant if true.

(1') $\mathrm{S}$ is asking whether $<_{\mathrm{P}}<_{\mathrm{Q}} \mathrm{A}$ closes the window $>$ is compatible with the set of all propositions which have a bearing on $\mathrm{Q}>$.

She points out that, in such a situation, it is mutually manifest too that $\mathrm{A}$ is able to close the window, and, as a consequence, (1) cannot be about A's physical ability to close the window but achieves relevance as an instantiation of A's ability to close the window. Groefsema further argues that, since $\mathrm{S}$ and $\mathrm{A}$ are having a conversation in a specific place (here and now), the only "relevant" enrichment of the LF of (1) is that the instantiation of A's ability be immediate. Thus $\left(1^{\prime \prime}\right)$ is fleshed out of (1').

(1') $\mathrm{S}$ is asking whether $<_{\mathrm{P}}<_{\mathrm{Q}} \mathrm{A}$ closes the window immediately $>$ is compatible with the set of all propositions which have a bearing on $\mathrm{Q}>$.

$\mathrm{A}$ is then invited to focus on all the evidence concerning the proposition that $<\mathrm{A}$ closes the window immediately>, that is, the evidence supporting his closing of the window (that there is a window open, that windows in general ought to be closed, that $\mathrm{A}$ is closer to the window than $\mathrm{S}$ is, ...). If at least one element is incompatible with the proposition $\mathrm{Q}, \mathrm{A}$ should give a negative answer to S's question (e.g., if the window in question is blocked, out of reach, and so cannot be closed). If there are no such elements incompatible with the proposition Q, A should give a positive answer to the question about her ability to immediately close the window. However, the proposition Q describes a state of affairs that does not hold at the time of utterance, and, therefore, the only relevant way for A to provide positive evidence for $\mathrm{Q}$ is to make sure that the state of affairs described by $\mathrm{Q}$ will hold at once. That is, the only way A can respond to the question (1) while satisfying the presumption of relevance is to close the window.

\footnotetext{
${ }^{3}$ See also Groefsema (1995). For a discussion of other relevance-theoretic accounts of modals, see Berbeira Gardón (1998) and Papafragou (2007).
} 
Groefsema's (1992) explanation of how processing the interrogative (1) yields a higherorder explicature of a "request" resembles very much the kind of rational reconstruction postulated by Searle (1975) insofar as, in her account, a question about A's (immediate) ability plays a role in understanding, and A must go beyond this interpretation to satisfy her expectation that S's behavior is relevant. Following Searle, who assumes Grice's (1975) view of how meaning is inferred, to identify the request meaning of (1), A should first reason that $S$ blatantly violates the maxim of conversational Relevance insofar as the answer to the question about A's ability to close the window is obvious (hence it is not relevant, in Grice's sens, to ask a question about A's ability). Assuming that $\mathrm{S}$ is nonetheless a cooperative speaker, A will try to identify the reason of this violation of the maxim of Relevance. Taking into account background knowledge and S's desires, he will recognize a content communicated beyond the literal meaning of the question, i.e., the meaning of a request. ${ }^{4}$ In a rather similar fashion, Groefsema's analysis suggests that possible interpretations of (1) that do not consist in a "request for action" assumption, such as an ability question, would be discarded as inappropriate relative to the context at hand.

Moreover, Groefsema's account raises an important issue. She focuses on requests involving can, such as (1), but other modals, such as will and should, and many other constructions are used in conventionalized IRs, such as Will you VP?, Why don't you VP?, Why not VP?, Shouldn't you VP?, Can I ask you to VP?, to mention just a few. Arguably, if uttered in appropriate circumstances, these constructions could be understood as requests in a very straightforward way. I fail to see how an approach based on claims about lexical meanings, such as Groefsema's, could account for these cases. If all of these expressions are formulaic qua requests, the author would have to postulate for each of them - in a rather ad hoc fashionthe same kind of analysis she proposes for can. As a result, Groefsema's argument for the existence of a request meaning for the modal can, which would be 'directly' accessed by the interpreter, emerges in a weakened position.

The upshot of this section is that, as in the case of the negative state remark (4), the request assumption communicated by means of the conventionalized (1) should be considered as an implicature rather than as an explicature. However, (4) and (1) differ as to the amount of inferential work required to access the request interpretation, the implicated request assumption being weaker in the former case. To see whether conventionalized IRs of the interrogative sentence-type, such as Can you VP?, are inferentially more complex than imperative requests, I will now examine the features that, according to relevance theory, these two sentence-types encode.

\section{Potentiality and desirability}

\subsection{Potentiality}

\footnotetext{
${ }^{4}$ A full reconstruction of the inferential steps leading A to the understanding of conventionalized IRs is offered in Searle (1975, 72-74).
} 
In Sperber \& Wilson's (1995) relevance theory, utterances are analyzed as stimuli that express mental representations or "thoughts". These stimuli can be used to describe states of affairs in the actual world, in alternative possible worlds, or in worlds compatible with the individual's assumptions about the actual world (potential worlds). A representation can either be used descriptively, as a representation of a state of affairs, or interpretively, by standing for another representation to which it bears a resemblance.

An important feature that is part of the semantics of imperative sentences is the notion of potentiality or "achievability". The idea is that, while imperative sentences do not depict states of affairs in a speaker's world, i.e., in her actual world, they nonetheless refer to states of affairs in alternative worlds. Wilson \& Sperber (1988) take "achievability", together with "desirability" (see Section 3.2), to compose the complex attitude that characterizes imperative sentences: imperatives are, according to them, specialized for descriptions of states of affairs in potential and desirable worlds. Likewise, interrogative sentences encode states of affairs that are presented as potential. That being said, it is unclear how this notion of achievability differs from related notions such as, for instance, ability and possibility.

While both imperatives and interrogatives are similar in that they express descriptions of potential states of affairs, they can be distinguished in terms of the sort of desirability they encode.

\subsection{Desirability in imperatives}

In RT, the use of the imperative is specialized for descriptions of states of affairs in worlds that are not only potential, but also desirable (Wilson \& Sperber 1988; Sperber \& Wilson 1995, 250251; see also Clark 1993, Carston 2002). That is, in RT, the notions of achievability and desirability, conceived of as attitudes towards propositional contents, are encoded by imperative sentences.

In fact, Sperber \& Wilson are not very explicit on what exactly they mean by desirable. According to them, desirability is a three-place relationship, where $\mathrm{X}$ regards $\mathrm{Y}$ as being desirable to Z. Concerning "serious" imperatives, they distinguish between two categories of speech acts depending on whether the state of affairs referred to by the imperative is desirable to the speaker or to the addressee. On the one hand, in directives, good wishes such as (10), audienceless cases such as (11), and predetermined cases such as (12), S indicates that the state of affairs is "desirable from her point of view" — which, as we will see below, is not necessarily equivalent to "desirable to her".

(10) Good night, Grandma. Sleep well. (Corpus of Contemporary American English, COCA)

(11) Please don't rain tomorrow.

(http://myandmythoughts.blogspot.be/2010/08/please-dont-rain-tomorrow.html)

(12) Please don't have made things worse. (Wilson \& Sperber 1988) 
On the other hand, in permission and advice (13)-(14), $\mathrm{S}$ indicates that the state of affairs is desirable from A's perspective.

(13) Take the first street (sharp right turn) at E. CC Street.

(http://www.columbiawillamettewine.org/program.html)

(14) A: Can I open the window?

B: Oh, open it, then. (Wilson \& Sperber 1988)

Within these two classes of speech acts performed with imperatives, subtler distinctions are made, depending on which additional contextual assumptions are involved. For instance, if it is manifest that $\mathrm{A}$ is able to bring about the truth of the propositional content of the sentence uttered, then the speech act will be a directive.

Let us apply the RT analysis to an imperative uttered as a directive speech act. In such a case, the semantic, incomplete, interpretation of the utterance is that its propositional content is achievable and desirable. For RT, the propositional form of the imperative sentence (15a) would be (15b) (Sperber \& Wilson 1995, 225).

(15) a. Close the window.

b. The addressee will close the window immediately.

The pragmatic interpretation of the imperative is delivered by resolving the semantic indeterminacy; in the case of a request such as (15a), this means understanding that the state of affairs represented in (15b) is desirable to $\mathrm{S}$. This leads to the assumption that $<$ "the door will be closed immediately" is desirable to $\mathrm{S}$ and achievable>. Thus the imperative sentence in (15a) may, but need not, convey the following assumptions:

(16) a. It is desirable to $\mathrm{S}$ and potential that A will close the window immediately.

b. S is telling A to make it true that A will close the window immediately.

Note that the proposition $<$ A closes the window $>$ or $<A$ will close the window immediately $>$ embedded in (16a-b), is not itself communicated, since it is represented in the imperative as achievable but not as actual (Carston 2002, 120).

Summing up, for RT, the imperative sentential mood does not encode directive force, but the propositional attitudes of achievability and desirability and, because of this, it gives the interpreter a general direction in which to seek relevance. I will show that, unlike in interrogatives and declaratives, in imperatives this general direction is action-oriented in the sense that imperatives are predisposed to the performance of directives. However, as I suggested above, at this stage a careful discussion of what exactly desirability consists in is required.

In Sperber \& Wilson's (1995) relevance theory, desirable from someone's point of view, desirable to someone, and beneficial to someone, are distinct expressions that are used in 
the discussion of the propositional attitude of desirability (see also Blakemore 1992, 110-114). Yet, inasmuch as the concept of desirability itself is not explicitly defined in RT, it is possible that these expressions actually refer to incompatible definitions of what it is for a state of affairs to be desirable. A critical examination of RT's desirability along these lines is provided by Dominicy \& Franken (2002, 269-271). These authors stress that one should distinguish between, on the one hand, desirable to and, on the other hand, desirable for. For example, I may entertain the desire to eat sweets while, at the same time, wanting to remain healthy. In other words, I may think of sweets as being desirable to me while believing that eating sweets is not desirable for me. Dominicy \& Franken's distinction between desirable to and desirable for shows that something that is desirable to someone is not necessarily desirable for that person, and vice versa. The problem in RT's account is that it is unclear whether desirability is conceived of in terms of desirable to or desirable for. The following example, proposed by Kissine (2013, 111), illustrates desirability for someone: a patient has undergone a risky operation, and the surgeon announces (17).

(17) We managed to save your leg, but forget about playing football again.

Even though the patient may entertain the desire to play football again, the doctor's utterance communicates that it is better for him, from a psychological point of view, not to consider such a possibility any longer, for instance to avoid feeling frustrated. Note that cases such as (17) will not constitute a problem for RT, as long as it can be argued that the state of affairs depicted by the imperative is desirable from someone's perspective. ${ }^{5}$

Thus additional clarification is required concerning how different notions of desirability are used within the RT framework. In spite of this shortcoming, however, it is safe to conclude that imperatives stand in sharp contrast to declaratives, which encode no propositional attitude of desirability whatsoever. Unlike declaratives (and, in a sense that we will see below, unlike interrogatives), imperatives encode an attitude of the speaker's that is oriented towards the addressee's performance of some action. I now turn to the sort of desirability involved in interrogative sentences, which are, in that respect, conceptually closer to imperatives than to declaratives.

\subsection{Desirability in interrogatives}

In their analysis of the meaning of interrogative sentences, Wilson \& Sperber (1988) also use a notion of "desirability", although in a somehow different way as the way they use it in their analysis of imperatives. In this former sense, a conceptual representation (a thought) or an assumption (a thought about the actual world) is desirable only if it is relevant, i.e., only if it

\footnotetext{
${ }^{5}$ Another concern with the relevance-theoretic analysis of imperatives in terms of desirability is voiced by Kissine (2013) and Jary \& Kissine (2014). Kissine (2013, 108-111) suggests that, if one assumes that second-person imperative sentences present a content as achievable, with an agent as subject, one should consider it as a general fact about the world, rather than a semantic property of imperative sentences, that such an achievable state of affairs may also be desirable for/to someone.
} 
yields enough cognitive effects to make it worth processing (Sperber \& Wilson 1995, 250-251). According to them, an interrogative is a representation that itself represents another thought in virtue of a resemblance between the two representations. In such cases, the first representation is used interpretively to represent what $\mathrm{S}$ takes to be relevant answers to the question expressed by the interrogative (Sperber \& Wilson 1995, 228-229). That is, interrogatives are doubly interpretive in that they represent a thought of the speaker's, which is itself a representation of another thought or utterance. For these authors, in the case of wh-interrogatives, the sentence is used as a representation of the complete proposition to which it bears resemblance. More precisely, an interrogative represents the completions of the incomplete logical form it expresses; $\mathrm{S}$ would regard an utterance expressing such a completion as relevant if true. For them, positive polar interrogatives such as (18) indicate that a positive answer would be more relevant than a negative one.

(18) Did you close the door?

For a negative polar interrogative such as (19), the negative answer would be more relevant, and for disjunctive interrogatives such as (20), both answers would be equally relevant. ${ }^{6}$

(19) Didn't you feel the same? (http://hellopoetry.com/poem/1881095/untitled/)

(20) Did you or did you not hurt and lie to each other??! (http://ew.com/recap/bigbrother-season-19-finale/)

According to RT, in order to resolve the semantic indeterminacy of interrogative sentences, A must make an assumption about the individual to whom $\mathrm{S}$ is suggesting that an answer to the question expressed would be regarded as desirable. Thus, at the pragmatic level, $\mathrm{S}$ may be taken as indicating that she regards the answer to the question as relevant either to herself or to A. The cases where the answer is regarded as relevant to $\mathrm{S}$ are "ordinary" questions (requests to answer questions), exam questions, "indirect" requests for action, guess questions, surprise questions, self-addressed questions. Further contextual assumptions are needed to distinguish between this variety of interpretations. For instance, exam and guess questions differ from ordinary questions in that they involve S's being manifestly in a better position than A to know the answer to the question expressed. The cases where the answer is regarded as relevant to A encompass expository and rhetorical questions. In expository questions, $\mathrm{S}$ makes it manifest that she knows the answer and is prepared to provide it, while in the case of rhetorical questions $\mathrm{S}$ manifests that she expects A to know the answer or to be in a position such that he can infer it by himself.

In sum, according to the standard RT approach, an interrogative sentence encodes, at the semantic level, the desirability of the possible answer(s) to the question it expresses, and

\footnotetext{
${ }^{6}$ Wilson \& Sperber (1988) suggest that the formal differences within interrogative sentence-types can be accounted for by taking into consideration differences of processing effort and cognitive effects for A. For example, the extra syntactic complexity of a disjunctive interrogative relative to a positive polar interrogative could be offset by the cognitive effect associated with the assumption that $\mathrm{S}$ is expressing her impatience or exasperation.
} 
the pragmatic interpretation of an interrogative is accessed through extra contextual assumptions. The important difference between the desirability encoded by interrogatives and that encoded by imperatives is that only the latter is oriented towards a state of affairs centred on the addressee.

We saw in Section 2 that, according to Groefsema's (1992) definition of modal can, a request use of Can you VP? is considered an explicature of the utterance. However, I argued that it was best thought of as a (strongly) implicated assumption. In comparison with Can you $V P$ ?, the imperative would make the request easier to access as an explicature.

(1) Can you close the window? (repeated)

(2) Close the window. (repeated)

The inferential route from S's utterance to the assumption that A's closing the window is desirable is expected, from a theoretical perspective, to be more straightforward in the case of the imperative (2) insofar as the desirable state of affairs is linguistically more salient in the case of the imperative, and it is not so for Can you VP?. It is not obvious, however, how these considerations translate into predictions concerning the processing of these expressions. In the next section, I address recent experimental evidence that sheds light on this issue.

\section{Maximal and optimal relevance}

Recall that, in Sperber \& Wilson's (1995) standard relevance-theoretic framework, A expects from S's contribution that the information she intends to convey will have a substantial cognitive effect that should compensate for additional interpretative effort required to process the utterance in question. Otherwise, nothing would warrant the search of further interpretations beyond a readily accessible meaning. The degree of relevance associated with an utterance might thus be conceived of as a ratio between the utterance's effects and the processing costs of that utterance for A. Maximal relevance is achieved, for any given degree of effort, when the effects resulting from that effort are maximized, or, for any given level of effects, when the effort required for deriving those effects is minimized (Sperber \& Wilson 1995, 142-151). Accordingly, if she is a cooperative speaker (cf. Grice 1975), S should choose the utterance that would achieve the highest "effects/costs ratio"-a stimulus that achieves maximal relevance. However, in line with the presumption of optimal relevance, A not only assumes that S's utterance is relevant enough for it to be worth A's processing effort: he expects $S$ to choose the most relevant stimulus that best matches her preferences and her abilities (Sperber \& Wilson 1995, 266-271). A stimulus that satisfies the presumption of optimal relevance, i.e., which is optimally relevant, may thus be a stimulus that is not maximally relevant. In the next two subsections, I address the issue whether conventionalized Can you VP? IRs are maximally or optimally relevant relative to imperative requests.

\subsection{Extra processing costs for conventionalized indirect requests?}


Before elaborating on the relevance-theoretic analysis of "indirect requests" in terms of processing costs and cognitive effects, let me return to (1) and the corresponding imperative (2).

(1) Can you close the window? (repeated)

(2) Close the window. (repeated)

I assume that interrogative Can you VP? sentences are comparable to imperative sentences insofar as both are plausible alternative ways to perform one and the same request speech act. Following the definition of maximal relevance, a request such as (1) would be more relevant in a given context than the imperative request in (2) only if the IR causes, in that context, extra cognitive effects absent in the imperative while entailing no extra processing costs relative to the imperative. Equivalently, the IR (1) would be more relevant in the same context if it reduces the processing costs in comparison with the imperative (2) while triggering the same (and no more) cognitive effects as the imperative does. Thus, to determine which alternative is maximally relevant, one needs to take into account both the processing costs and the cognitive effects associated with these expressions in the specific context in which one or the other is uttered. Here, I will only consider the processing costs involved at the pragmatic level. Possible differences between imperative and indirect requests in terms of syntactic processing are difficult to assess from a purely theoretical perspective, and it is unclear in RT whether the effort involved in decoding has a bearing on the relevance of a stimuli.

We saw in Section 3.3 that interrogative sentences are interpretively used to convey what for $\mathrm{S}$ counts as a desirable answer, i.e., an answer that causes positive effects for the interpreter. Likewise, the imperative mood encodes the propositional attitude of desirability. However, I have argued that, from a RT perspective, a request that A close the window is communicated as an explicature in the case of an imperative, but as a strong implicature in the case of Can you VP?. In addition, I have suggested that, relative to the interrogative mood, the imperative mood makes a "request assumption" easier to access than an interrogative construction such as Can you VP?. As a consequence, one expects IRs such as (1) to increase the processing costs for the interpreter, unless the inferential process is somehow facilitated.

According to Vega Moreno $(2007,116)$, "recurrent selective processing of a familiar stimulus [for instance, a token of Can you VP?] may lead to the development of a more or less automatic cognitive procedure or inferential route to process this stimulus". Her notion of "pragmatic routine" strongly suggests that actual cognitive processing of Can you VP? utterances should involve a reduction of the number of inferential steps required to understand their IR meaning $(2007,116-119)$. In the same vein, Escandell-Vidal $(2004,357)$ proposes that a higher accessibility of background assumptions can guide the addressee towards the correct interpretation-from her perspective social representations "are ready to be used in the inferential processing" $(2004,360)$. The use of pragmatic routines would thus enable interpreters to short-circuit the extra inferential steps necessary to infer the meaning of 
conventionalized IRs (cf. Morgan 1978) relative to imperative requests, with, as a result, no extra processing costs for the former relative to the latter.

Several experimental studies provide support for the view that pragmatic routines enable the minimization of the processing effort for conventionalized IRs. For instance, it has been demonstrated that, providing the context is supportive of such interpretations, conventionalized IRs are recognized as fast as their "direct" literal counterparts (e.g., the question reading of Can you VP?), and that inferring their "request" meaning does not require the prior derivation of their literal meaning (Gibbs 1979, 1983; see also Abbeduto et al. 1989; Shapiro \& Murphy 1993).

In a study devoted to the Pouvez-vous VP? construction (the closest counterpart - albeit not similar in meaning in all its uses - of English Can you VP?), Ruytenbeek et al. (2017) compared the French Pouvez-vous VP ? IRs with imperative requests. The act-out task consisted in 24 combinations of a recorded spoken sentence with a grid containing coloured shapes on the computer screen, with "yes" and "no" buttons at the bottom of the screen. For half of the Pouvez-vous VP? stimuli, such as (21), it was possible for the participants to move the shape as indicated in the sentence, for the other half such a move was impossible (and the only possible response was a "no" answer).

(21) Pouvez-vous mettre le cercle vert à gauche du carré rouge?

'Can you move the green circle to the left of the red square?'

(22) Mettez le cercle vert à gauche du carré rouge.

'Move the green circle to the left of the red square.'

The participants listened to each sentence and responded to it either with yes/no or by moving a shape in the grid. This study replicates previous findings for the English conventionalized Can you VP?: no difference in response times was found between the request interpretation of Pouvez-vous VP? and that of the imperative. In addition, Pouvez-vous VP ? stimuli gave rise to virtually null durations of fixation on the "yes"/"no" buttons (the same finding holds for imperative requests): in that respect, this experiment supplements previous work on IR interpretation, showing that the absence of extra processing times for ability interrogative IRs correlates with the absence of activation of the utterance's literal "question" meaning. This study also demonstrates the possibility to operationalize cognitive effects and to measure processing efforts. $^{7}$ Its highly controlled experimental design ensured that, relative to imperative stimuli, the request interpretations of ability sentences would not cause any extra cognitive effect for the participants/interpreters.

\footnotetext{
${ }^{7}$ A criticism that is sometimes addressed to RT is that it does not explain how to quantify processing costs and cognitive effects (see Davis 1998, 103; Bach 2006). As for processing costs, Dan Sperber once proposed that, since processing effort amounts to energy consumption, it should be measured in joules (relevance theory list, 2006; the page is no longer accessible).
} 
As we saw in the studies devoted to IRs in English discussed above, a valuable advantage of Can you VP? is that it entails no extra processing effort relative to the imperative: both types of stimuli can thus achieve maximal relevance in the performance of requests. Another question is: Is it possible that IRs give rise to extra cognitive effects absent in imperatives, which would make them more relevant than imperatives?

\subsection{Extra cognitive effects?}

The question to be explored in this section is the following. Should the politeness associated with Can you VP? IRs be considered as an extra cognitive effect that makes them more relevant, all other things being equal, than imperatives? Or, rather, is the politeness of IRs best thought of in terms of speakers' desire to avoid being perceived impolite?

Social considerations such as linguistic politeness are sometimes conceived of as reasons for opting for indirect requests instead of imperative ones (Searle 1975, 64; Brown \& Levinson 1987, 71-84). In classic Brown \& Levinson's (1987) theory, directive speech acts constitute face-threatening behavior. A's freedom to do only what he wants to and his will that others do not impede his actions ("negative face") are threatened when S puts him more or less strongly under the obligation to perform an action. In this perspective, the choice of a polite expression reflects S's desire to minimize the face-threats for A's negative face that are associated with the performance of a directive. According to Brown \& Levinson (1987, 130144), if S wants to avoid such emotional costs for A, while at the same time making her communicative intention clear enough, she resorts to conventionalized expressions such as $\mathrm{Can}$ you VP?.

A natural intuition is that in these IRs, a higher degree of politeness would justify the use of IRs instead of imperatives (Jacobsen 2010). The explanation is somewhat different for an expression such as (23), which, when uttered, can receive a rather impolite reading, e.g., implying that $\mathrm{A}$ is a non-cooperative person and thus threatening A's positive face (his want to be approved of).

(23) Can't you close the window?

It is plausible that, in cases such as (23), impolite implications are cognitive effects for the addressee that would compensate for the extra complexity of the negative utterance.

Appearances notwithstanding, it is doubtful that the degree of politeness or impoliteness communicated is sufficient to make Can you VP? requests more relevant than imperative ones. As Jary $(1998$ b , 2) points out, very often politeness does not attract attention, so that, pace Brown \& Levinson $(1987,95)$, there is no specific level of meaning at which politeness is communicated. Arguing that, in many cases, politeness does not belong to the intended message, Jary (1998b, 13) refuses to attribute to linguistic politeness the status of a conveyed propositional content. Under this view, it does not make sense to assume that Can you VP? requests systematically communicate politeness. 
In contrast to Jary (1998b), it seems that Escandell-Vidal $(1998,52)$ would analyse the politeness assumption communicated with a conventionalized IR as a higher-level implicature such as (24), which embeds another level of implicature (that of the request assumptionassuming, of course, that the IR meaning of a Can you VP? stimulus is implicated).

(24) S told me to close the door, and she did it politely.

She illustrates this sort of analysis with an impolite imperative utterance (Get out!) that she characterises as being impolite. Because the request meaning of the imperative Get out! is an explicature (see Section 2), the "impoliteness assumption" that "S told me to get out, and she did it in a rude way" would also be communicated as a higher-order explicature. Thus, for an imperative request, the request assumption and the impoliteness assumption both are explicatures of the utterance.

Although she acknowledges that inferential judgments of im/politeness can in theory occur for every utterance, Escandell-Vidal claims that politeness is rarely communicated. For an im/politeness assumption to be communicated, two conditions are required: im/politeness must be both intentional and manifest. This implies that, in many contexts, the implicature in (24) will not be derived, which makes Escandell-Vidal's analysis closer to Jary's than it seems at first glance. In the same vein, Terkourafi $(2003,2008)$ considers politeness, impoliteness and rudeness as perlocutionary effects of S's utterance. A politeness or impoliteness assumption can, but need not, be achieved as a consequence of S's utterance (Terkourafi, 2003).

Culpeper's (2011: 186-193) experimental work provides support for the idea that conventionalized IRs are unmarked in terms of im/politeness. Culpeper asked graduate students to rate utterances such as (25) (imperative request), (26) (conventionalized indirect request) and (27) (negative state remark or "non-conventionalized indirect request") on a scale of increasing impoliteness in two different conditions.

(25) You be quiet.

(26) Could you be quiet?

(27) You aren't being quiet.

In the "High - Low" power condition (H-L), three basic scenarios were displayed: a boss addressing an employee, a judge speaking to a defendant, and a sergeant-major addressing a recruit. In the "Low - High" power condition (L-H), the speaker and addressee roles were reversed. On the 7-point scale, a score of 0 corresponds to "strongly disagree" to the statement that the utterance is impolite, and a score of 6 to "strongly agree". In the H-L power condition, all three types of utterances were considered to be less impolite than in the L-H condition, the mean rating in H-L condition being "disagree somewhat" (score of 2). To be more precise, in the H-L condition, the mean scores for direct, conventionalized IRs and negative state remarks were all below the neutral score of 3 ("neither agree nor disagree"), with a markedly low score for conventionalized indirectness such as (26). Since power plays an important role in $\mathrm{im} /$ politeness judgments, we can assume that if considerations of hierarchy, status and power 
are less salient, utterances such as (26) will be unlikely to give rise to assumptions about their being polite or impolite.

Finally, the results of an experimental study of email requests in French support the thesis that the sort of politeness associated with the use of indirect requests does not constitute a communicated assumption or a cognitive effect for the interpreter (Ruytenbeek, in press). In this experiment, participants — students, native speakers of French-were asked to send an email to another person to ask that person for a contribution in a student journal. The status of the addressee was manipulated: for half of the participants, the addressee was the Dean of the Faculty (higher-status condition), for the other half it was a female student (equal-status condition). Overall, 66\% of the requests consisted in Could you VP? interrogatives such as (28):

(28) Pourriez-vous m’envoyer le texte que vous avez rédigé pour la revue ?

'Could you send me the text you wrote for the journal?'

A detailed analysis of the request forms indicates that the French equivalent of conventionalized Could you VP? (Pourriez-vous VP?) requests were no more frequent in the higher-status condition than in the equal-status condition. Instead of increasing the politeness of their message with Could you VP? when they addressed a higher-status person, the participants used specific linguistic devices, such as formal greetings and polite $\mathrm{V}$-forms of address. As we will see in the next section, if ability interrogatives Can you VP? are frequently used in the performance of requests in British and American English conversations (Flöck 2016), this preference is best accounted for in terms of speakers' desire to avoid being perceived as impolite.

\subsection{Speaker's preferences}

Thus far, we have focused on IRs' cognitive effects for addressees. However, the performance of IRs can also be approached from the perspective of the speaker's preferences. These preferences would, for instance, motivate the speaker's choice of a conventionalized IR without it causing any extra effect for the addressee.

On the one hand, Hickey $(1992,79-80)$ distinguishes four types of motivations that could justify the use of conventionalized indirect utterances instead of direct utterances. These motivations relate to the semantic content of the utterance, the expression of emotions or attitudes, the perlocutionary effects provoked on the addressee, and the properties of the surface form of the utterance.

Why, by virtue of its semantic content and its interrogative sentence-type, is Can you $V P$ ? often chosen for the performance of requests? The explanation I propose is the following. Even though Can you VP? does not always give rise to extra cognitive effects about politeness or perlocutionary effects absent in imperatives, this expression is preferred to the imperative because it is considered polite qua expression (cf. Terkourafi 2015). In the words of cognitive linguists, Can you VP? encodes, by virtue of its lexical semantics, a force dynamic pattern of “enablement" (Johnson 1987, 52-53; Sweetser 1990, 52-53; Talmy 2000, 444-447). 
Accordingly, can refers to the addressee's internal capacity or "power" to act. Unlike imperatives (and also You must VP declaratives), the force dynamic pattern of Can you VP? cannot directly be specified with force exertion at the pragmatic level. Even though noncompliance is possible both with indirect directives and direct directives such as imperatives, non-compliance is, in a sense, easier with Can you VP? because, at the semantic level, interrogatives express questions. This does not mean that Can you VP? needs to be interpreted as a speech act of questioning, but questions about A's ability identify very general obstacles to the performance of the expected action (cf. Francik \& Clark 1985), which provides A with options to justify his non-compliance.

On the other hand, Davis $(1998,119)$ points out that central matters for S regard the amount of efforts she produces in conveying her assumptions and the possible consequences of the utterance's form for her reputation (see also Lee \& Pinker 2010). In a similar vein, according to Jary (1998b, 2-3), the choice of "polite" forms such as conventionalized IRs is, above all, explained by S's desire to preserve her status within a social community. Discussing the difference between imperative and non-imperative requests, Jary (1998a, 160) argues that in communicating her desire by means of an imperative, $S$ makes manifest her belief that this desire is relevant for $\mathrm{A}$. The recognition of this premise is required for $\mathrm{A}$ to access the intended interpretation. For Jary, the choice of conventionalized indirect linguistic forms for making requests is motivated by S's further desire to avoid conveying hazardous implications such as the assumption that, since her desire is relevant to A, S is somewhat "superior" to A. Thus, according to Jary's approach, if a non-imperative expression is selected over an imperative in a particular situation, the reason is that it matches S's preferences better than an imperative would do.

Note that, however, A's compliance with a non-imperative request such as Can you VP? implies that S's desire is relevant to A, just as it is when the corresponding imperative is uttered. That is, S's desire will be relevant for A whether the sentence is imperative, interrogative or declarative. In all such cases, understanding that a request has been made implies that $S$ 's desire has been perceived as a reason to obey. Thus Jary's point is that, while both imperative and indirect requests may convey the unwanted implicature that $\mathrm{S}$ is superior to A, IRs are less likely than imperatives to do so because of their linguistic content (force dynamic pattern of enablement, see above) and their interrogative sentence-type.

The upshot of this section is that one cannot conclude that an utterance of conventionalized Can you VP? will necessarily be more relevant than that of an imperative request, the reason being that, in some contexts, the politeness associated with the former is unlikely to count as an extra cognitive effect absent in the latter. Rather, available experimental evidence supports the view that Can you VP? utterances, unlike their imperative counterparts, are optimally relevant stimuli when they are used as requests because they enable speakers to avoid impoliteness.

\section{Conclusion}


In this paper, I have outlined a standard relevance theoretic account of conventionalized Can you VP? IRs. If, as I have argued, the request assumption of a Can you VP? utterance is communicated as an implicature, extra inferential steps should be entailed relative to an imperative utterance, in which the request is communicated as an explicature. However, recent experimental evidence indicated that, in some situations, this extra inferential work does not translate into extra processing costs, which points to the facilitative role that pragmatic routines play in IRs understanding. This implies that both Can you VP? and imperative stimuli can achieve maximal relevance in the performance of requests. While politeness effects can, in theory, be triggered by conventionalized indirect expressions, the sort of politeness associated with these expressions generally goes unnoticed, and it is, therefore, unlikely that they communicate politeness as an extra cognitive effect. However, IRs requests differ from imperative requests in the sense that the former match speakers' preferences more than imperatives do: they enable them to avoid being perceived as impolite. As a consequence, unlike the imperative sentence-type, uttering the conventionalized Can you VP? can be optimally relevant for the performance of requests in many situations. In this paper, I have tried, for the sake of the argument, to abstract as much as possible from the particular features of the contexts in which imperative requests and IRs are performed. But, of course, such generalizations do not do justice to the variety of situations in which Can you VP? requests take place. The processing costs and cognitive effects of these expressions deserve more attention on a case-by-case basis.

Sperber \& Wilson $(1995,155-163)$ themselves pointed out that, even if the search for relevance underlies language comprehension as a natural default, all individuals are not necessarily equally sensitive to considerations of relevance. These inter-individual differences also raise the issue of when extra processing costs should give rise to a compensation in terms of cognitive effects, insofar as all cognitive effects need not result in increased costs, and vice versa. I agree, however, with Gibbs \& Tendahl (2006), who stress that RT need not make any specific claims as to whether additional costs increase the number of cognitive effects. Another interesting aspect of the research on IR interpretation is that considerations of costs and effects, which are central to the relevance theoretic framework, open new perspectives for experimental approaches concerning the processing of utterances in general. Such an avenue of research would be well in line with current developments in experimental pragmatics and psycholinguistic approaches to moment-by-moment utterance interpretation and politeness (for a review, see Holtgraves \& Bonnefon 2017 and Ruytenbeek 2017).

Finally, I would like to emphasize once more that the issues addressed in this paper cannot be answered on theoretical grounds only. Although Sperber \& Wilson (1995) consider that cognitive effects cannot be measured in an objective way, they suggest that, because cognitive effects and processing effort cause symptomatic physico-chemical changes, it is in principle possible to study how the human mind allocates its resources during utterance interpretation. Further investigation is welcome to provide additional empirical support to the analysis outlined in this paper, in particular on the side of cognitive effects. 


\section{References}

Bach, Kent, 2006. Impliciture vs explicature: what's the difference? Granada workshop on "Explicit Communication," in honor of Robyn Carston, May 31-June 2, 2006.

Berbeira Gardón, José L. 1998. Relevance and modality. Revista Alicantina de Estudios Ingleses 11, 3-22.

Brown, Penelope, Levinson, Stephen, 1987 (1978). Politeness: some universals in language usage. CUP, Cambridge; New York.

Carston, Robyn, 2002. Thoughts and utterances: the pragmatics of explicit communication. Blackwell, Oxford.

Carston, Robyn, 2009. The explicit-implicit distinction in pragmatics and the limits of explicit communication. International Review of Pragmatics 1, 35-62.

Clark, Billy, 1993. Relevance and pseudo-imperatives. Linguistics and Philosophy 16 (1), 79121.

Clark, Herbert H., 1979. Responding to indirect speech acts. Cognitive Psychology 11: 430477.

Culpeper, Jonathan, 2011. Impoliteness: using language to cause offence. CUP, Cambridge.

Davis, Wayne, 1998. Implicature. CUP, Cambridge.

Escandell-Vidal, Victoria, 1998. Politeness: a relevant issue for Relevance Theory. Revista Alicantina de Estudios Ingleses 11, 45-57.

Escandell-Vidal, Victoria, 2004. Norms and principles: putting social and cognitive pragmatics together. In Márquez-Reiter, R. and Placencia, M. E. (Eds.), Current Trends in the Pragmatics of Spanish. Benjamins, Amsterdam, 347-371.

Flöck, Ilka, 2016. Requests in American and British English. Benjamins, Amsterdam/Philadelphia

Francik, Ellen P., and Herbert H. Clark. 1985. How to make requests that overcome obstacles to compliance. Journal of Memory and Language 24, 560-568.

Gibbs, Raymond W., and Markus Tendahl, 2006. Cognitive effort and effects in metaphor comprehension: Relevance theory and psycholinguistics. Mind \& Language 21 (3), 379403.

Grice, Henry P. 1975. Logic and Conversation. In Cole, P. \& Morgan, J. L. (Eds.) Syntax and Semantics. Vol. 3, Speech Acts, 41-58. New York: Academic Press.

Groefsema, Marjolein, 1992. "Can you pass the salt?”: A short-circuited implicature? Lingua 87, 103-135.

Groefsema, Marjolein, 1995. Can, may, must and should: A Relevance theoretic account. Journal of Linguistics 31 (1), 53-79.

Hickey, Leo, 1992. Politeness apart: why choose indirect speech acts? Lingua e Stile 27 (1), 77 87.

Holtgraves, Thomas R. 1994. Communication in context: Effects of the speaker status on the comprehension of indirect requests. Journal of Experimental Psychology: Learning, Memory, and Cognition 20 (5): 1205-1218. 
Holtgraves, Thomas R., and Jean-François Bonnefon. 2017. Experimental approaches to linguistic (Im)politeness. In The Palgrave Handbook of Linguistic (Im)politeness, 381-401. Palgrave Macmillan.

Jacobsen, Ronald R. 2010. The interpretation of indirect speech acts in relevance theory. The Journal of Linguistic and Intercultural Education 3, 7-24.

Jary, Mark, 1998a. Is relevance theory asocial? Revista Alicantina de Estudios Ingleses 11, 157169.

Jary, Mark, 1998b. Relevance theory and the communication of politeness. Journal of Pragmatics 30, 1-19.

Jary, Mark, 2013. Two types of implicature: material and behavioral. Mind \& Language 28 (5): 638-660.

Jary, Mark, Kissine, Mikhail, 2014. Imperatives. CUP, Cambridge.

Johnson, Mark. 1987. The Body in the Mind. Chicago: University of Chicago Press.

Lee, James J., Pinker, Steven, 2010. Rationales for indirect speech: the theory of the strategic speaker. Psychological Review 117 (3), 785-807.

Morgan, Jerry L., 1978. Two types of convention in indirect speech acts. In Cole, P. (Ed.), Syntax and Semantics 9: Pragmatics. Academic Press, New York, 261-280.

Panther, Klaus-Uwe, and Linda Thornburg. 1998. A cognitive approach to inferencing in conversation. Journal of Pragmatics 30, 755-769.

Papafragou, Anna, 2007. Modality: Issues in the Semantics-Pragmatics Interface. Bingley: Emerald.

Pérez Hernández, Lorena, 2013. Illocutionary constructions: (Multiple source)-in-target metonymies, illocutionary ICMs, and specification links. Language and Communication 33, 128-149.

Ruytenbeek, Nicolas. 2017. The Comprehension of Indirect Requests: Previous Work and

Future Directions. In Depraetere, I. and R. Salkie (Eds.), Semantics and Pragmatics:

Drawing a Line, 293-322. Amsterdam: Springer.

Ruytenbeek, Nicolas. (in press). Do indirect requests communicate politeness? An experimental study of conventionalized indirect requests in French email communication? Journal of Politeness Research.

Ruytenbeek, Nicolas, Ostashchenko, Ekaterina, Kissine, Mikhail. 2017. Indirect request processing, sentence-types and illocutionary forces. Journal of Pragmatics 119, 46-62.

Searle, John R., 1975. Indirect Speech Acts. In Cole, P. and Morgan, J. L. (Eds.), Syntax and Semantics 3: Speech Acts. Academic Press, New York, 59-82.

Sperber, Dan, Wilson, Deirdre, 1995. Relevance: Communication and Cognition (second edition). Blackwell, Oxford.

Sperber, Dan, Wilson, Deirdre, 1997. The mapping between the mental and the public lexicon. UCL Working Papers in Linguistics 9.

Sweetser, Eve E., 1990. From Etymology to Pragmatics: Metaphorical and Cultural Aspects of Semantic Structure. Cambridge: Cambridge University Press. 
Talmy, Leonard. 2000. Toward a Cognitive Semantics. Vol. 1, Concept Structuring Systems. Cambridge, MA: MIT Press.

Terkourafi, Marina, 2003. Generalized and particularized implicatures of linguistic politeness. In Kühnlein, P., Rieser, H. and Zeevat, H. (Eds.), Perspectives on Dialogue in the New Millennium. Benjamins, Amsterdam/Philadelphia, 149-164.

Terkourafi, Marina, 2008. Toward a unified theory of politeness, impoliteness, and rudeness. In Bousfield, D. and Locher, M. A. (Eds.), Impoliteness in Language, Studies on its Interplay with Power in Theory and Practice, Language, Power and Social Process 21. Mouton de Gruyter, Berlin, 45-74.

Terkourafi, Marina, 2015. Conventionalization: A new agenda for im/politeness research. Journal of Pragmatics 86: 11-18.

Vega Moreno, Rosa E., 2007. Creativity and Convention, the Pragmatics of Everyday Figurative Speech. Benjamins, Amsterdam/Philadelphia.

Wilson, Deirdre, Sperber, Dan, 1988. Mood and the analysis of non-declarative sentences. In Dancy, J., Moravcsik, J. and Taylor, C. (Eds.), Human Agency: Language, Duty and Value. Stanford University Press, Stanford (CA), 77-101.

Wilson, Deirdre, Sperber, Dan, 1993. Linguistic form and relevance. Lingua 90, 1-25.

Wilson, Deirdre, Sperber, Dan, 2002. Relevance Theory. UCL Working Papers in Linguistics 14, 249-290. 